\section{Lung pathology in septic shock}

B CORRIN Cardiothoracic Institute, Hospital, London SW3 6HP, UK

Brompton

The lungs are particularly susceptible to blood-borne toxins by virtue of their anatomical position, and in septic shock they are one of the most frequently damaged organs. ${ }^{1}$ The principal changes are similar to those in traumatic shock and consist of congestive atelectasis or oedema, caused by events in the pulmonary microvasculature.

Endotoxin stimulation of the sympathetic nervous system and adrenal medulla initially causes intense constriction of both arterioles and venules. Acidosis subsequently leads to vasodilatation but this involves the arterioles primarily, resulting in stagnant congestion of the capillaries. ${ }^{2}$ Surfactant secretion is impaired, and the combination of congestion and collapse, so-called congestive atelectasis, is the basic pathological feature of shock lung. ${ }^{3}$ (Figs 1 and 2).

Further events in the pulmonary microvasculature include polymorph sequestration (Fig. 3) and fragmentation with the release of lysosomal enzymes. ${ }^{45}$ This damages the capillary endothelium, leading to increased permeability. ${ }^{56}$ Oedema and epithelial damage augment the surfactant deficiency and hence alveolar collapse. There is also often marked platelet aggregation in the pulmonary capillaries 7 with fibrin deposition and the formation of 'globular hyaline microthrombi'8 (Fig. 4) Megakaryocytes in the pulmonary capillaries also increase in number ${ }^{9}$ (Fig. 5), presumably reflecting the premature release of these platelet precursors from the bone marrow. Along with the accumulation of such blood elements in the lung there is neutropenia and thrombocytopenia. ${ }^{1011}$ The alterations in the pulmonary microcirculation often represent part of a generalised Schwartzman reaction, in which they may play an initiating role responsible for similar changes in other organs.

Damage to the alveolar epithelium caused by lysosomal enzymes and hypercapnia may proceed as far as necrosis, and the necrotic cellular debris together with fibrin may result in the formation of hyaline membranes (Fig. 6). The non-specific pathology of the adult respiratory distress syndrome is then present. ${ }^{12}{ }^{13}$ Although these later steps in the process may be brought about entirely by shock, in hospital practice they often accompany resuscitative efforts, which may themselves damage the lungs,

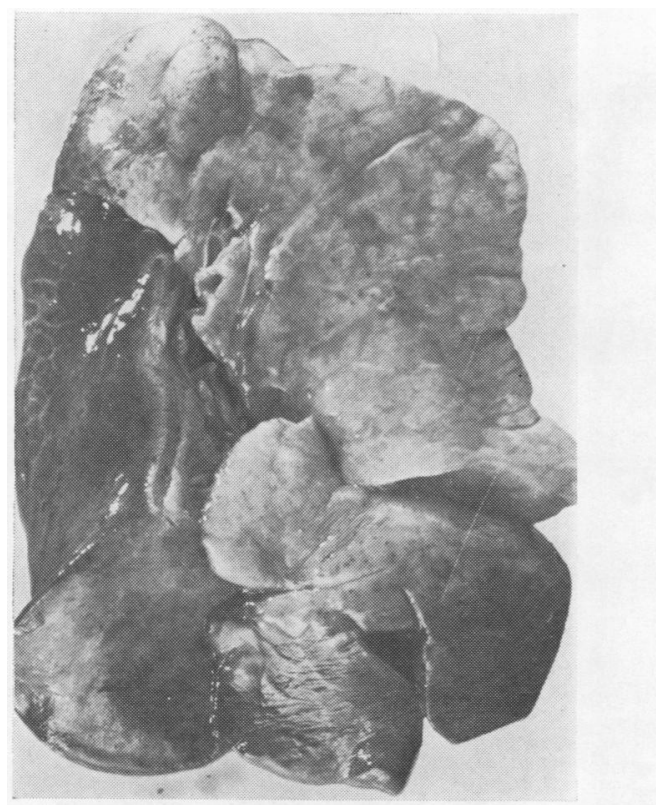

(a)

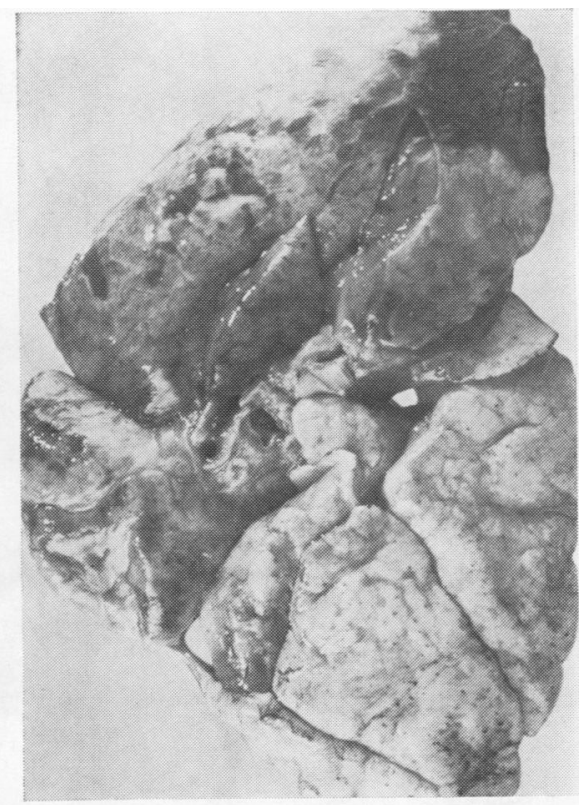

(b)

Fig. 1 Left (a) and right (b) lungs showing the post-mortem appearances in septic shock. There are irregular areas of congestion and collapse, affecting most of the left lower lobe and parts of the right upper lobe. $\times 1 / 3$. 


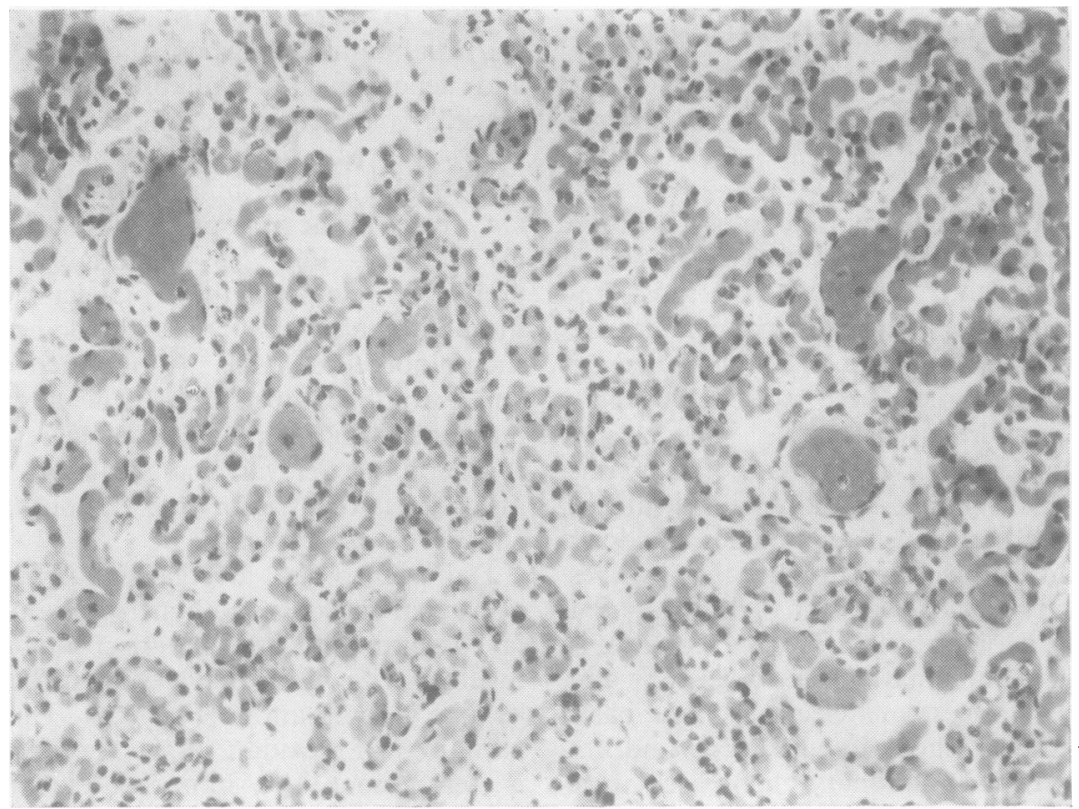

Fig. 2 Microscopy shows engorgement of the capillaries and alveolar collapse.

Haematoxylin and eosin $(H$ and $E) \times 190$.

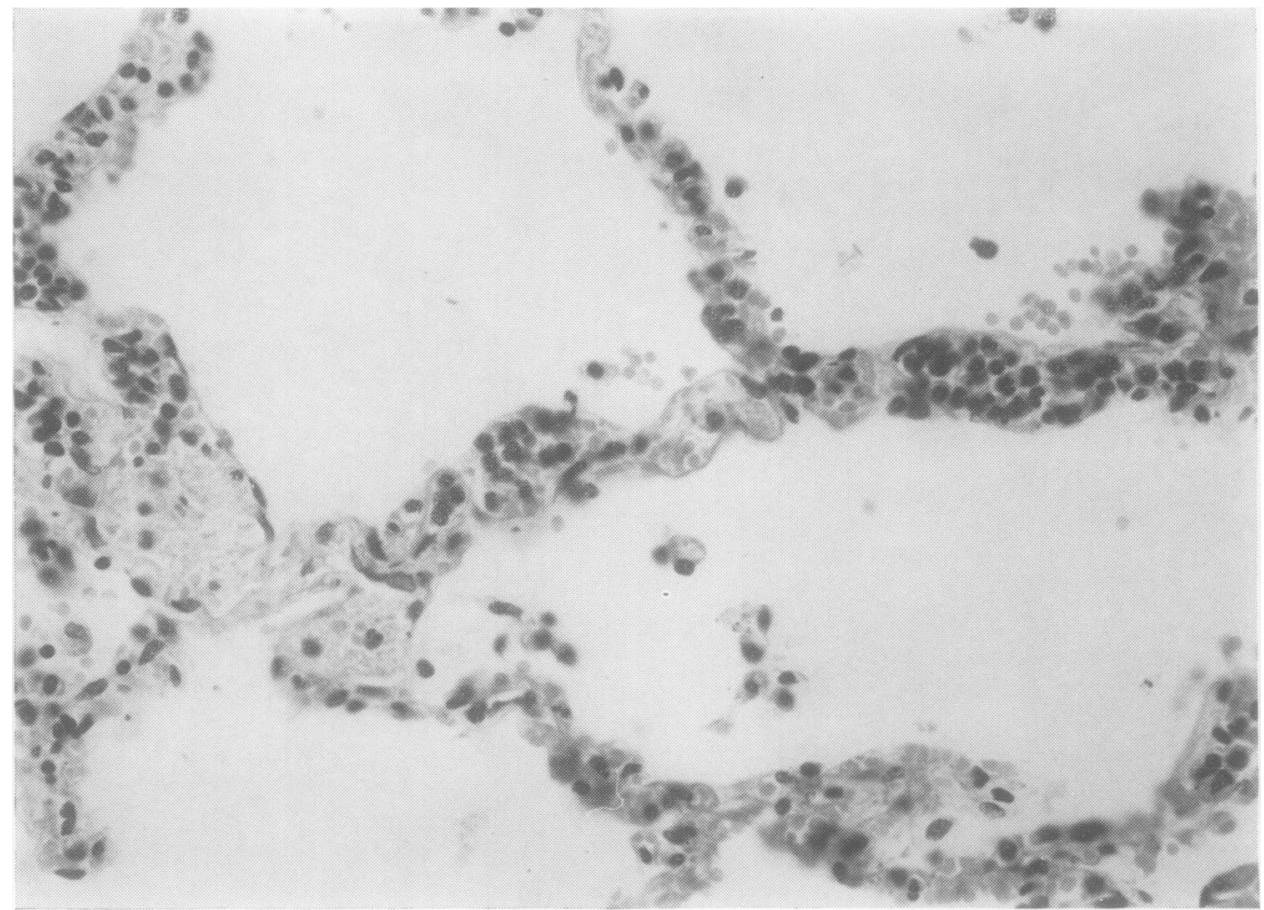

Fig. 3 Pulmonary capillaries showing polymorph sequestration. Note the absence of polymorphs from the alveoli, suggesting that infection is not the cause of polymorph accumulation in the capillaries. $H$ and $E \times 360$. 


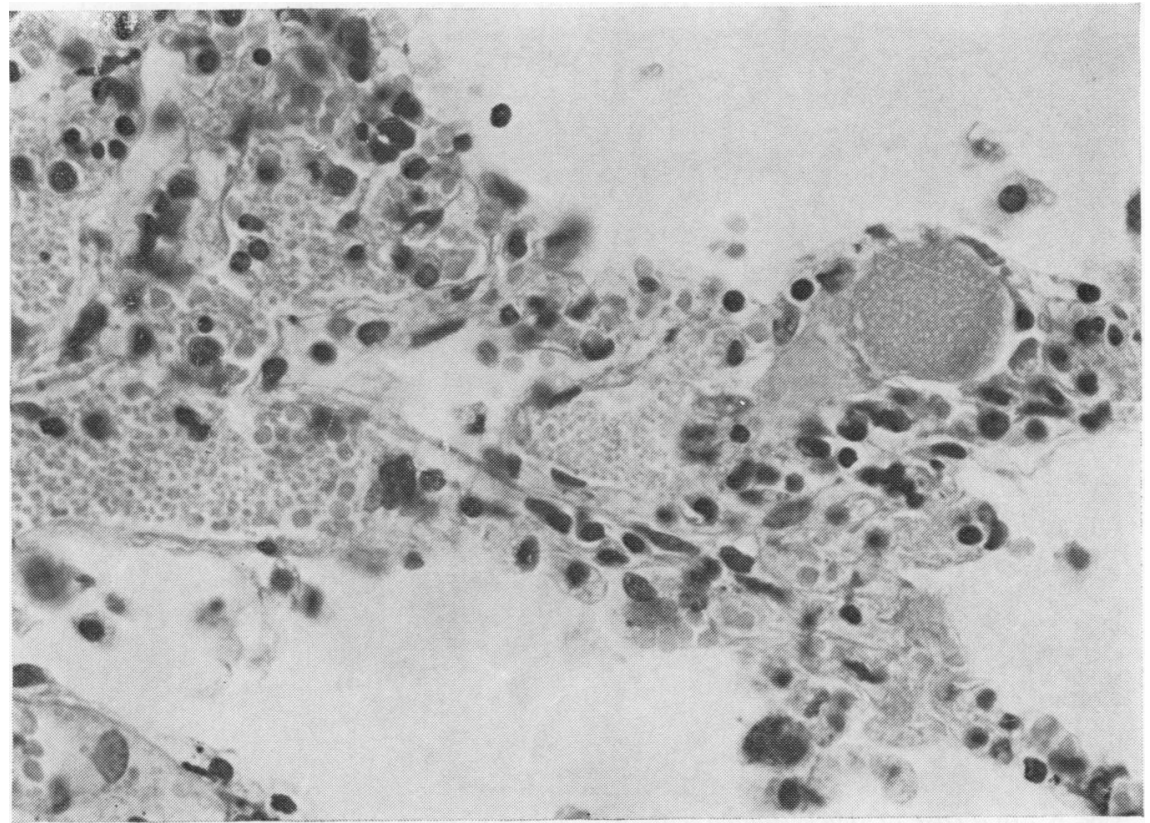

Fig. 4 Pulmonary capillaries showing platelet aggregation and a globular hyaline microthrombus. $H$ and $E \times 560$.

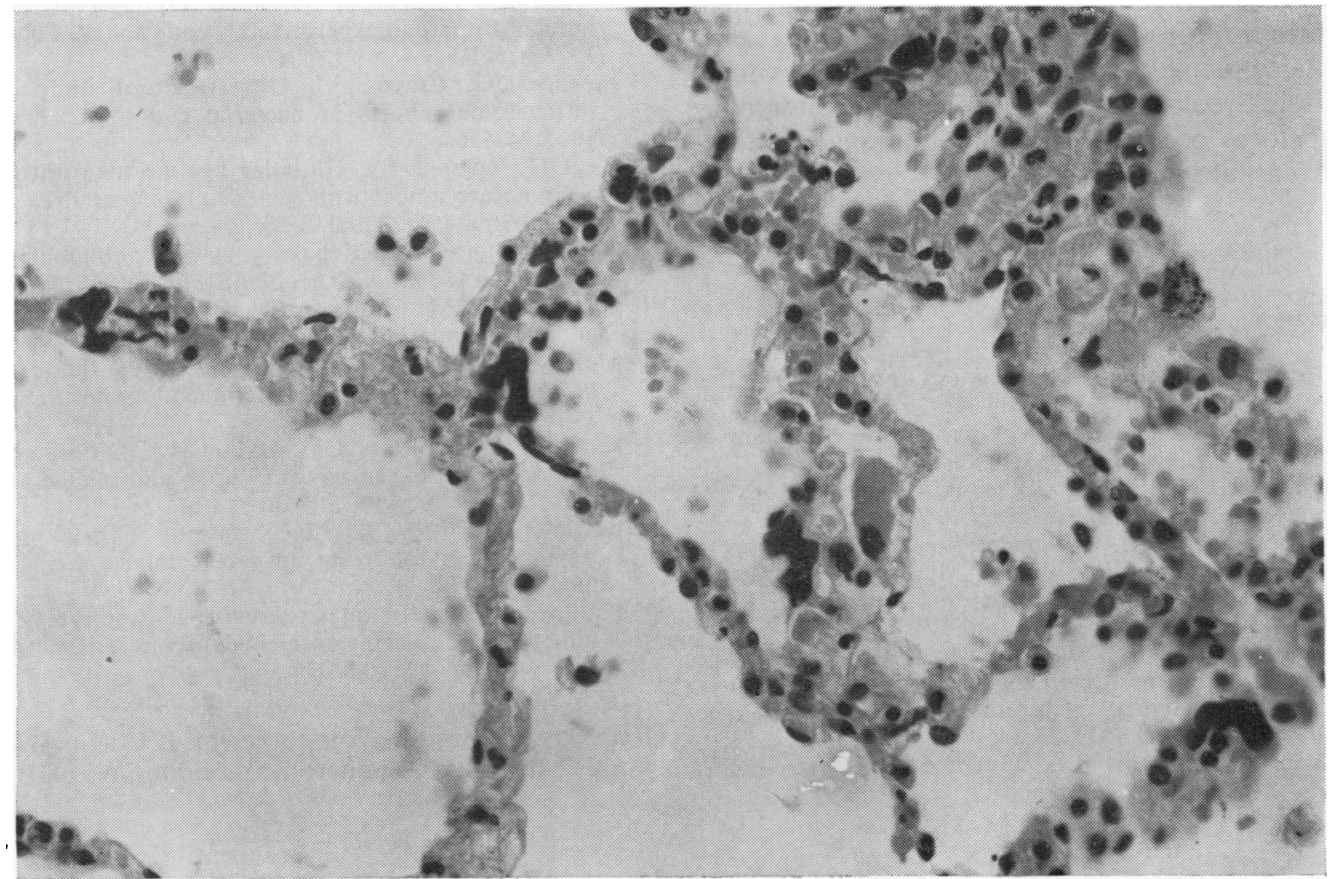

Fig. 5 Irregular haematoxyphil bodies in the pulmonary capillaries are megakaryocytes. Normally, these are very scanty, and the four seen in this high-power field indicate excessive release of these precursor cells, suggesting platelet consumption and disseminated coagulation. $H$ and $E \times 330$. 


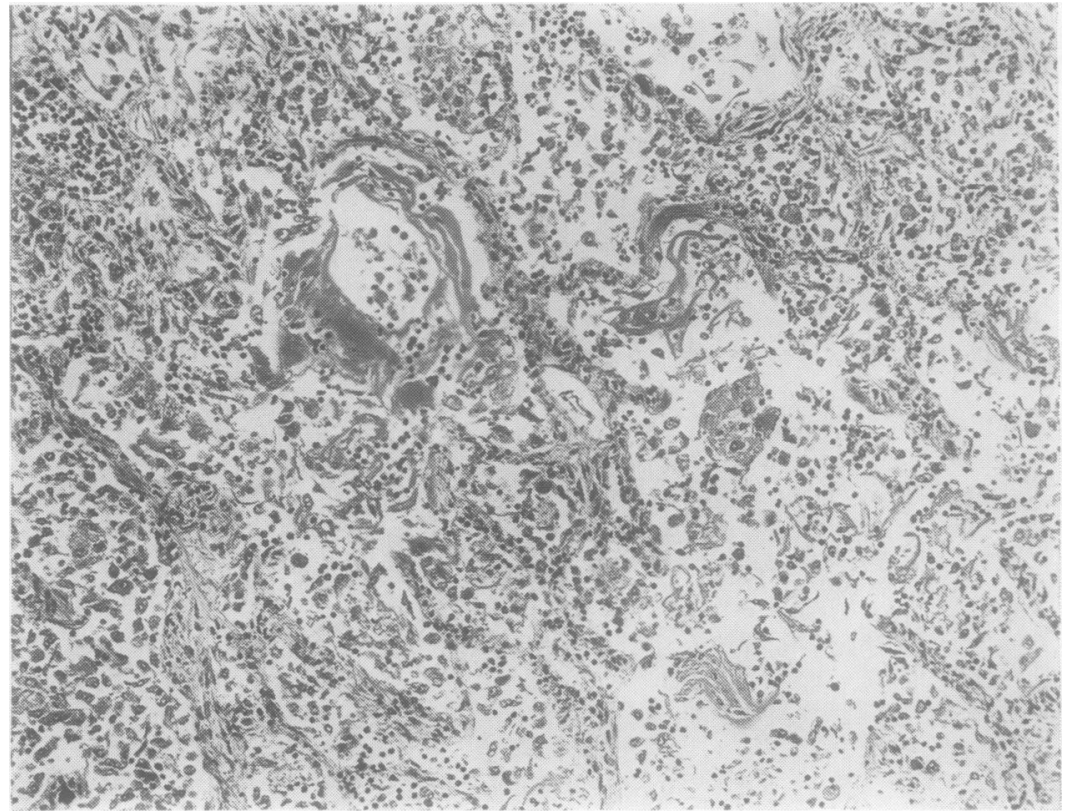

Fig. 6 In a case of shock treated with artificial respiration and oxygen, hyaline membranes line the interalveolar septa. These membranes consist of fibrin and cellular debris and indicate alveolar epithelial necrosis. $H$ and $E \times 100$.

particularly the administration of oxygen in high concentration for prolonged periods. The lungs may be further endangered by the infusion of large-volume crystalloidal solutions and infections facilitated by tracheostomy or originating in contaminated mechanical ventilators. ${ }^{14}$

\section{References}

${ }^{1}$ McGovern VJ. The pathophysiology of gram-negative septicaemia. Pathol 1972;4:265-71.

${ }^{2}$ Dietzman RH, Lillehei RC. The nature and treatment of shock. Br J Hosp Med 1968;1:300-4.

${ }^{3}$ Schramel R, Hyman A, Keller CA, Woolverton W. Congestive atelectasis. J Trauma 1968;8:821-6.

${ }^{4}$ Horn RG, Collins RD. Fragmentation of granulocytes in pulmonary capillaries during development of the generalised Schwartzman reaction. Lab Invest 1968; 19:451-9.

${ }^{5}$ Pingleton WW, Coalson JJ, Hinshaw LB, Guenter CA. The effect of steroid pre-treatment on development of shock lung. Haemodynamic, respiratory, and morphologic studies. Lab Invest 1972;27:445-56.

${ }^{6}$ Coalson JJ, Hinshaw LB, Guenter CA, Berrell EL,
Greenfield LJ. Pathophysiologic responses of the subhuman primate in experimental septic shock. Lab Invest 1975;4:561-9.

${ }^{7}$ McKay DG, Csavossy 1. Ultrastructural study of the intravascular effects of bacterial endotoxin. Fed Proc $1965 ; 24: 456$.

${ }^{8}$ Bleyl U, Rossner JA. Globular hyaline microthrombitheir nature and morphogenesis. Virchows Arch Pathol Anat Histol 1976;370:113-28.

9 Aabo K, Hansen KB. Megakaryocytes in pulmonary blood vessels. Acta Pathol Microbiol Scand A 1978;86:285-91.

${ }^{10}$ Hardaway RM, Johnson D. Clotting mechanism in endotoxin shock. Arch Intern Med 1963;112:775-82.

${ }^{11}$ McKay DG, Shapiro SS. Alterations in the blood coagulation system induced by bacterial endotoxin. J Exp Med 1958;107:353-67.

${ }^{12}$ Katzenstein AA, Bloor CM, Leibow AA. Diffuse alveolar damage - the role of oxygen, shock and related factors. Am J Pathol 1976;85:210-28.

${ }^{13}$ Bachofen M, Weibel ER. Basic pattern of tissue repair in human lungs following unspecific injury. Chest 1974 65:145-85.

${ }^{14}$ Phillips I. Pseudomonas aeruginosa respiratory tract infections in patients receiving mechanical ventilation. J Hyg (Lond) 1967;65:229-35.

Requests for reprints to: Professor B Corrin, Cardiothoracic Institute, Fulham Road, London SW3 6HP, UK. 